\title{
Fenologia do dendezeiro e correlações com variáveis climáticas
}

\author{
The phenology of oil palm and correlations with climate variables
}

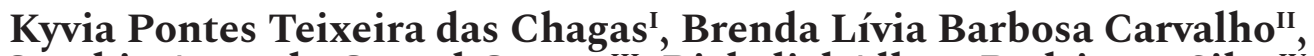 \\ Cynthia Azevedo Gurgel Guerra' ${ }^{\mathrm{II}}$, Richeliel Albert Rodrigues Silva ${ }^{\mathrm{Iv}}$, \\ Fábio de Almeida Vieira ${ }^{\mathrm{V}}$
}

\begin{abstract}
Resumo
O presente trabalho teve como objetivo descrever a fenologia de uma população natural de Elaeis guineensis (dendezeiro), localizada na Unidade Acadêmica Especializada em Ciências Agrárias da UFRN, em Macaíba - RN, avaliando-se as fenofases reprodutivas e vegetativas das plantas e o comportamento das variáveis climáticas nestas fenofases. Foram registradas quinzenalmente, de outubro de 2012 a março de 2014, as características fenológicas referentes a enfolhamento, desfolhamento, antese e frutificação, avaliadas por meio do índice de atividade e intensidade de Fournier. A relação entre as variáveis climáticas e as fenofases foi realizada por meio da correlação de Spearman. Elaeis guineensis não apresentou emissões de botões e flores no período avaliado. A perda e a emissão de folhas ocorreram durante todo o tempo. A atividade de frutos imaturos apresentou correlação significativa e positiva com a temperatura $\left(r_{\mathrm{s}}=0,336 ; P=0,03\right)$. A intensidade e a atividade dos frutos maduros apresentaram, respectivamente, correlação positiva e significativa tanto com a umidade $\left(r_{s}=0,455 ; P=0,004\right.$ e $\left.r_{s}=0,416 ; P=0,009\right)$ quanto com a precipitação $\left(r_{s}\right.$ $=0,614 ; P=0,00004$ e $\left.r_{s}=0,578 ; P=0,0001\right)$, indicando que quanto maior umidade e precipitação, maior é a produção de frutos maduros.
\end{abstract}

Palavras-chave: Fournier; Precipitação; Óleo de palma

\begin{abstract}
This study aimed to describe the phenology of a natural population of Elaeis guineensis (oil palm), located on the Academic Unit Specialized in Agricultural Sciences UFRN in Macaíba, RN state, evaluating reproductive and vegetative phenological phases of plants and the climate. Phenological characteristics concerning leafiness, defoliation, blooming and fruiting, evaluated using the activity index and intensity of Fournier recorded biweekly from October 2012 to March 2014. The relationship between climate and the phenological phases was performed by Spearman correlation. Elaeis guineensis showed no emission of buds and flowers. The loss and leaf emergence occurred during the whole time. The activity of immature fruits showed significant positive correlation with temperature $\left(r_{s}=0.336, P=0.03\right)$. The intensity and activity of mature fruits showed, respectively, a significant positive correlation with both humidity $\left(r_{s}=\right.$ $0.455, P=0.004$ and $\left.r_{\mathrm{s}}=0.416, P=0.009\right)$ and with rainfall $\left(r_{\mathrm{s}}=0.614, P=0.00004\right.$ and $\left.r_{\mathrm{s}}=0.578, P=0.0001\right)$, indicating that the higher humidity and precipitation, the greater the production of the ripe fruit is.
\end{abstract}

Keywords: Fournier; Precipitation; Palm oil

Engenheira Florestal, MSc., Universidade Federal do Rio Grande do Norte, Unidade Acadêmica Especializada em Ciências Agrárias, RN 160 - Km 03 - Distrito de Jundiaí, CEP 59280-000, Macaíba (RN), Brasil. kyviapontes@gmail.com (ORCID: 0000-0003-1361-3204)

II Advogada, Pesquisadora Autônoma, Av. Alm. Alexandrino de Alencar, 2409, Lagoa Nova, CEP 59030-350, Natal (RN), Brasil. brendaliviabc@ hotmail.com (ORCID: 0000-0002-1482-0179)

III Engenheira Florestal, Universidade Federal do Rio Grande do Norte, Unidade Acadêmica Especializada em Ciências Agrárias, RN 160 - Km 03 Distrito de Jundiaí, CEP 59280-000, Macaíba (RN), Brasil. cynthiaguerra93@gmail.com (ORCID: 0000-0001-7741-2132)

Iv Engenheiro Florestal, MSc., Universidade Estadual do Centro Oeste, Rua Professora Maria Roza Zanon de Almeida, Engenheiro Gutierrez, CEP 84505-677, Irati (PR), Brasil. richeliel@yahoo.com.br (ORCID: 0000-0002-8098-4155)

Engenheiro Florestal, Dr., Professor do Departamento de Engenharia Florestal, Universidade Federal do Rio Grande do Norte, Unidade Acadêmica Especializada em Ciências Agrárias, RN 160 - Km 03 - Distrito de Jundiaí, CEP 59280-000, Macaíba (RN), Brasil. vieirafa@gmail.com (ORCID: 00000003-3347-255X) 


\section{Introdução}

Elaeis guineensis Jacq., conhecida como dendezeiro, é uma monocotiledônea perene da família Arecaceae, comum na América do Sul e originária da África tropical (HAYATI et al., 2004). Caracteriza-se, reprodutivamente, como uma planta monoica, produzindo inflorescências femininas e masculinas na mesma planta, as quais se alternam em um ciclo de duração variável que depende de fatores genéticos, condições ambientais e idade do vegetal. Estas características favorecem a polinização cruzada, uma vez que esporadicamente as plantas femininas e masculinas ficam, ao mesmo tempo, suscetíveis à polinização (CORLEY et al., 1976). Ademais, o vegetal tem, preponderantemente, polinização entomófila. Segundo Genty et al. (1986), os principais polinizadores associados ao dendê na América Latina são os insetos pertencentes à família Nitidulidae (Mystrops costaricensis Gillogly) e Curculionidae (Elaeidobius subvittatus Faust).

No Brasil, o dendezeiro é encontrado, principalmente, em fragmentos de Mata Atlântica e na região nordeste, sendo também largamente difundido na região norte do país, principalmente em plantios extrativistas (SILVA; CAVALCANTI, 2010; LORENZI, 2004). A palmeira tem destaque no mercado de consumo por produzir um óleo de elevado valor econômico, o qual tem potencial elevado para a produção de biodiesel e é, também, muito utilizado na produção de gêneros alimentícios. De acordo com Lin et al. (2009), o dendezeiro está entre as espécies que mais produz óleo vegetal comestível no mundo.

O óleo de dendê pode ser extraído da polpa, sendo comumente chamado de óleo de palma; ou pode ser extraído da amêndoa, o qual é conhecido como óleo de palmiste. Há mais de 12 milhões de hectares plantados com dendê no mundo e devido à intensa produção mundial de óleos e gorduras vegetais, além do uso do biodiesel na Europa e em alguns países da América do Sul, o consumo do óleo de dendê tende a aumentar substancialmente (FEDEPALMA, 2010), e mesmo por sua importância econômica são necessários mais estudos de caracterização física de frutos e sementes, pois as pesquisas nessa área são incipientes.

Quanto à fenologia da Elaeis guineensis, pouco se conhece sobre o padrão de distribuição espacial e temporal das fenofases. Esta abordagem é de suma importância tanto para a ecologia, quanto para o melhoramento genético e a agrometeorologia, visto que a fenologia objetiva estudar a época de ocorrência de fenômenos naturais repetitivos, relacionados principalmente com o clima, já que os processos como o desfolhamento, estão diretamente ligados a ele (FISCH et al., 2000).

Fatores como a temperatura média, a umidade relativa do ar e a precipitação podem influir diretamente nas fenofases da planta (VILELA et al., 2008), pois são elementos externos que acionam mecanismos fisiológicos, fazendo com que os indivíduos alterem seu metabolismo de acordo com as situações ambientais (ADLER; LAMBERT, 2008). Dessa forma, com o conhecimento da fenologia reprodutiva e vegetativa da Elaeis guineensis em uma escala temporal e espacial, geramse subsídios importantes para definir estratégias de conservação e melhoramento da espécie.

Este trabalho teve como objetivo estudar o padrão fenológico, reprodutivo e vegetativo, por meio de avaliações das fenofases de floração, frutificação, queda e brotação foliar de uma população de Elaeis guineensis, situada no município de Macaíba, no Rio Grande do Norte.

\section{Material e métodos}

\section{Área de estudo}

O trabalho foi realizado em uma área pertencente à Unidade Acadêmica Especializada em Ciências Agrárias da Universidade Federal do Rio Grande do Norte - UFRN, nas coordenadas $5^{\circ} 52^{\prime} 54^{\prime}$ 'S $35^{\circ} 21^{\prime} 45^{\prime}$ W, no município de Macaíba - RN. Segundo Köppen, o clima da região é uma transição entre os tipos As' e BSh', com temperaturas elevadas ao longo de todo o ano (média 
de $27,1^{\circ} \mathrm{C}$ ) e chuvas no outono e no inverno (precipitação média de $1.058,1 \mathrm{~mm}$ ). A área tem como vegetação predominante a Caatinga e, segundo o IBGE (1992), é classificada como Floresta Estacional Semidecidual de Terras Baixas, com deciduidade ao final do período desfavorável, tendo-se a presença de ação antrópica, com vegetação secundária.

\section{Fenologia vegetativa e reprodutiva}

Foram amostrados aleatoriamente 20 indivíduos de Elaeis guineensis, com altura superior a 5 metros, em uma população natural (Figura 1). Em seguida, observaram-se os eventos fenológicos entre os meses de outubro de 2012 e março de 2014, totalizando 38 observações quinzenais ao longo de todo o período.

Figura 1 - Distribuição espacial dos indivíduos de Elaeis guineensis. Os eixos indicam as coordenadas geográficas em UTM (Universal Transversa de Mercator).

Figure 1 - Spatial distribution of individuals of Elaeis guineensis. The axes indicate the geographical coordinates in UTM (Universal Transversa de Mercator).

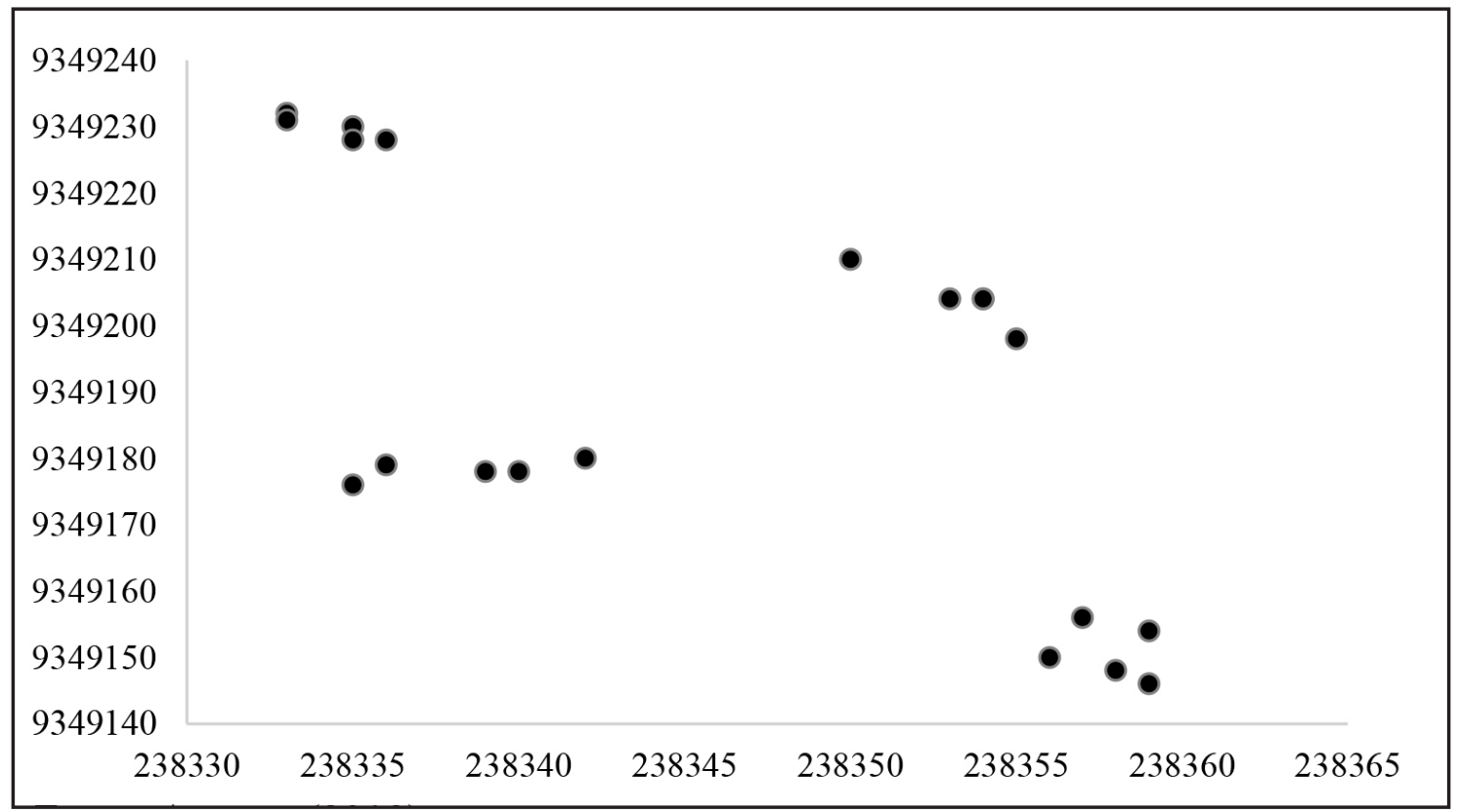

Fonte: Autores (2019)

As fenofases avaliadas foram: enfolhamento, desfolhamento (Figura 2A), flores masculinas e frutos imaturos (Figura 2B), e frutos maduros (Figura 2C). A fenologia foi relacionada com os dados diários de temperatura, umidade relativa e precipitação da área local, dados estes, obtidos através do Projeto de Monitoramento da Evaporação e Mudanças Climáticas do Rio Grande do Norte (MEVEMUC), executado no sítio do Laboratório de Variáveis Ambientais Tropicais (LAVAT). As avaliações das fenofases foram feitas com o auxílio de um binóculo Bushnell ${ }^{\circledR}$ com aumento de 10x, consistindo de observações na copa das palmeiras, onde se encontram as folhas, flores e frutos. 
Figura 2 - Enfolhamento e desfolhamento (A), flores masculinas e frutos imaturos (B), e frutos maduros $(\mathrm{C})$ em uma população de Elaeis guineensis em Macaíba - RN.

Figure 2 - Leafiness and defoliation (A), male flowers and immature fruit (B), and ripe fruits (C) in a population of Elaeis guineensis in Macaíba, RN state.

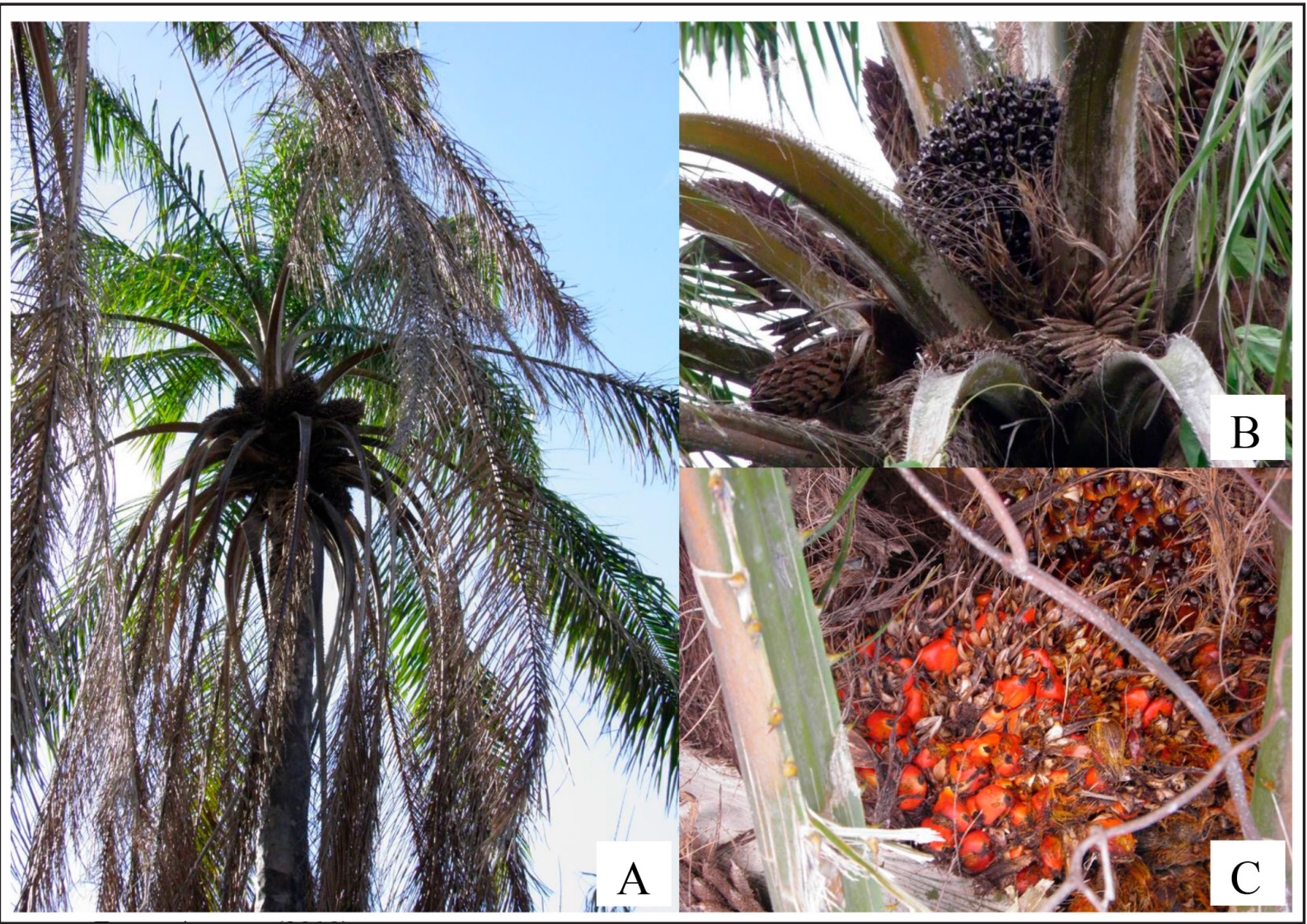

Fonte: Autores (2019)

Pelo método direto qualitativo, foi avaliado o índice de atividade dos eventos fenológicos, verificando-se a presença ou ausência dos eventos na espécie. Já no método direto semiquantitativo de Fournier (1974), foi avaliada a intensidade das fenofases pelo índice de Fournier, utilizandose uma escala intervalar semiquantitativa de cinco categorias ( 0 a 4$)$, com intervalo de $25 \%$ entre cada categoria: zero $=$ ausência de fenofase, $1=$ presença da fenofase com magnitude atingindo entre 1 e $25 \%, 2$ = presença de fenofase com magnitude atingindo entre $26 \%$ e 50\%, 3 = presença de fenofase com magnitude atingindo entre $51 \%$ e $75 \%$ e 4 = presença de fenofase com magnitude atingindo entre $76 \%$ e $100 \%$.

\section{Análises estatísticas}

Para a realização da análise estatística dos dados, foi utilizado o programa estatístico Statistica 10 (STATSOFT INC., 2011). Desvios da normalidade dos dados fenológicos foram confirmados pelo teste de Kolmogorov-Smirnov, para uso da correlação não paramétrica de Spearman $(r)$, a qual foi realizada com os dados climáticos da primeira quinzena anterior ao evento fenológico. 


\section{Resultados e discussão}

\section{Condições climáticas}

No decorrer do período de análises, a máxima temperatura observada foi de $27,82^{\circ} \mathrm{C} \mathrm{em}$ fevereiro de 2013 , sendo a mínima de $24,2^{\circ} \mathrm{C}$, em agosto de 2013 . No que tange à temperatura média mensal, durante o lapso de tempo amostrado, pode-se afirmar que os dados foram relativamente constantes e altos por todo o tempo (Figura 3A). Além disso, a época mais úmida entre os meses de avaliação foi em julho de 2013 , com uma média de $81,52 \%$ de umidade relativa do ar; e a menos úmida foi em novembro de 2013 , com uma média de $61,85 \%$. Todavia, as médias mensais de umidade mostraram pouca variação no decorrer dos meses/anos amostrados (Figura 3B).

Quanto à precipitação, a região apresentou baixos valores, de 2012 a 2014 . O mês mais chuvoso, dentre a época de estudo, foi o mês de janeiro de 2013. No entanto, o ano de 2013 apresentou picos pluviométricos também nos meses de maio, julho e setembro, tendo uma precipitação anual de 1220,23 mm (Figura 3C).

Figura 3 - Dados médios das variáveis climáticas de temperatura $\left({ }^{\circ} \mathrm{C}\right)(\mathrm{A})$, umidade relativa do $\operatorname{ar}(B)$ e precipitação $(\mathrm{mm})(\mathrm{C})$ para um ano e meio de avaliação (2012 a 2014) em Macaíba - RN.

Figure 3 - Average data of climate variables temperature $\left({ }^{\circ} \mathrm{C}\right)(\mathrm{A})$, relative humidity $(\mathrm{B})$ and precipitation $(\mathrm{mm})(\mathrm{C})$ for a year and a half evaluation (2012 to 2014) in Macaíba, RN state.

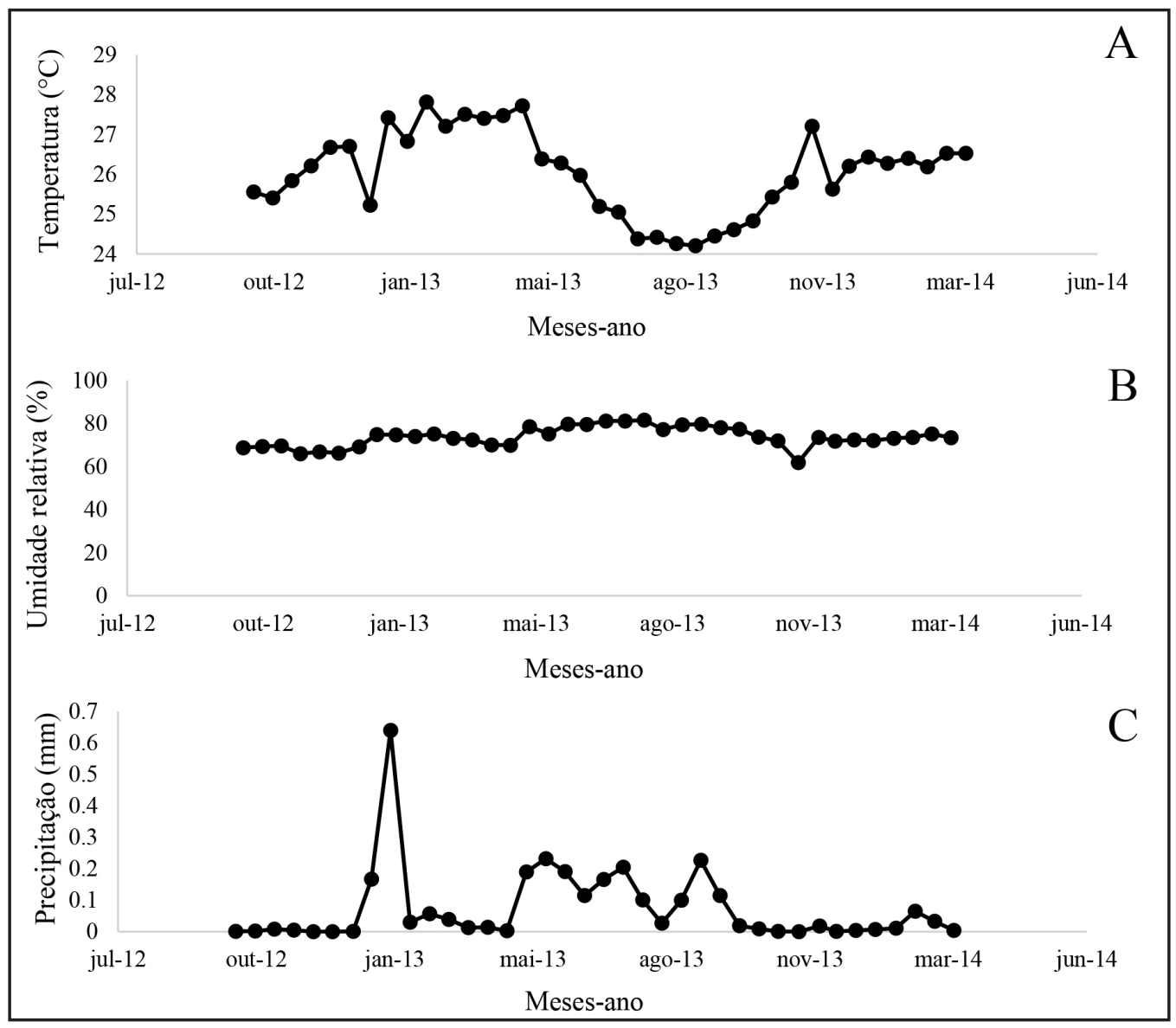

Fonte: Autores (2019) 


\section{Comportamento fenológico do dendezeiro}

O desfolhamento da Elaeis guineensis foi intenso durante todo o período de observação. As intensidades variaram de $26 \%$ a $60 \%$ ao longo do estudo, sendo em setembro de 2013 e primeiros meses de 2014, o intervalo de maior intensidade de desfolhamento (Figura 4A). A perda de folhas é uma resposta natural às influências bióticas e abióticas e quando em excesso, pode ser justificada pela presença de pragas ou mesmo pela ausência de um fenômeno ambiental, como a precipitação, a intensidade luminosa e a disponibilidade de gás carbônico (ALENCAR, 1994). Rebelatto et al. (2013) atribuíram o intenso desfolhamento à ação mecânica do vento, a qual ocasiona o rompimento prematuro das zonas de abscisão foliares. Ademais, o deficit hídrico é um provável indutor da fenofase de desfolhamento (CORLETT, 1993).

Além disso, a sucessão de folhas novas resultou na variação de $70 \%$ a $100 \%$ do índice da atividade. O índice de intensidade variou entre $23 \%$ e $45 \%$, sendo os meses de maio a julho de 2013 , os de menores intensidades (Figura 4B). Em estudos com outras espécies, os autores sugerem que folhas novas surgem em decorrência do desfolhamento no período seco, a estresses ambientais e a estratégias fisiológicas, e fato recorrente em espécies tropicais em que, normalmente, a queda foliar parece induzir o brotamento (HUETE et al., 2006; REICH e BORCHERT, 1984; BARBOSA et al., 1989).

Assim, observou-se que houve produção ininterrupta de folhas novas durante o período. Esse resultado é comum para as espécies florestais, uma vez que estudos referentes à fenologia, no que tange ao enfolhamento, mostraram-se semelhantes, como a avaliação realizada por Anderson et al. (1988) com a palmeira babaçu (Orbignya phalerata Mart.) e Scariot et al. (1991), com a palmeira macaúba (Acrocomia aculeata Jacquin). Esse contínuo enfolhamento e desfolhamento, com emissão e perda de folhas ao longo do intervalo de análises sugere uma dessincronia entre indivíduos dessa espécie.

\section{Figura 4 - Padrão fenológico para o desfolhamento (A) e enfolhamento (B) em uma população natural de Elaeis guineensis em Macaíba - RN.}

Figure 4 - Phenological standard for defoliation (A) and leafiness (B) in a natural population of Elaeis guineensis in Macaíba, RN state.

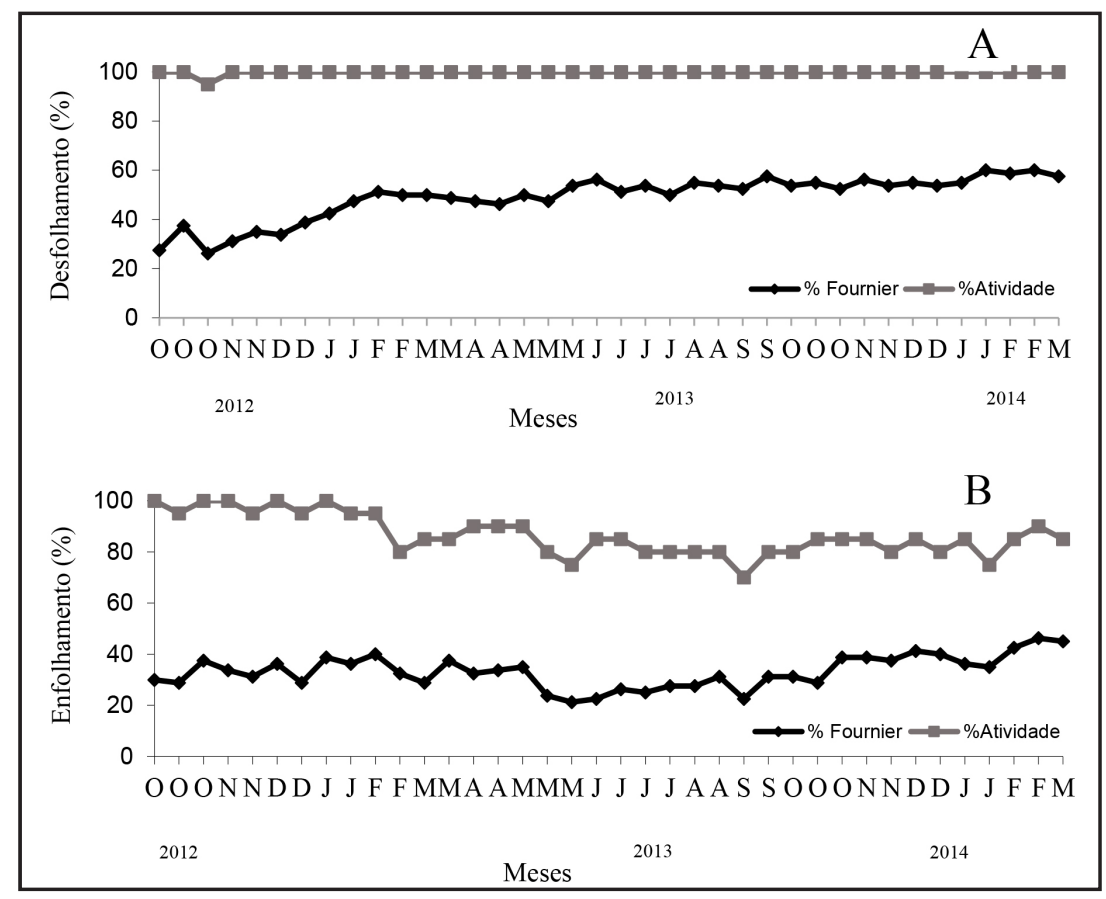

Fonte: Autores (2019) 
Já com relação à fase reprodutiva da Elaeis guineensis, devido à altura da copa dos indivíduos não foi possível observar atividade e intensidade dos botões. Essa circunstância pode ser resultado do fato de que a espécie possui o desenvolvimento reprodutivo prejudicado pelo ambiente em que se encontra, produzindo menos inflorescências e em menores tamanhos. Bergert (2000) infere que os deficit hídricos são uma das principais causas na redução da produção de cachos de frutos, além de estimular a formação de inflorescências masculinas. Adam et al. (2005), estudando a complexidade do desenvolvimento reprodutivo da Elaeis guineensis, observaram que, em indivíduos adultos, a inflorescência se desenvolve ao longo de 2 anos e é caracterizado por fases individuais em que a diferenciação pode ser tanto relativamente lenta, como no caso da rápida inflorescência do meristema em desenvolvimento, quanto rápida, como no processo de organogênese.

A frutificação da Elaeis guineensis ocorre mais de uma vez no ano, sendo assim uma espécie subanual. Os frutos imaturos apresentaram maior atividade durante os meses de janeiro e fevereiro de 2013 e fevereiro de 2014, tendo uma variação de 15 a 90\% durante o período avaliado. A intensidade também se apresentou maior nos meses de janeiro e fevereiro de 2013 e fevereiro de 2014, com uma variação de 5 a 35\% (Figura 5A).

Com relação aos frutos maduros, estes apresentaram maior atividade e intensidade nos meses de janeiro e fevereiro de 2013. Porém, durante os meses de outubro e novembro de 2012 e outubro, novembro e dezembro de 2013, houve uma baixa atividade e intensidade de frutos maduros. A atividade variou de 0 a $75 \%$ e a intensidade de Fournier variou de 0 a $26 \%$ (Figura 5B). Esse baixo índice de produção de frutos maduros pode estar associado às baixas precipitações do local, visto que, para a produção de frutos carnosos, a água é um fator substancial (TABARELLI et al., 2003).

Figura 5 - Padrão fenológico para os eventos de frutos imaturos $(A)$ e frutos maduros $(B)$ em uma população natural de Elaeis guineensis em Macaíba - RN.

Figure 5 - Phenological standard for immature fruit events (A) and ripe fruits (B) in a natural population of Elaeis guineensis in Macaíba, RN state.

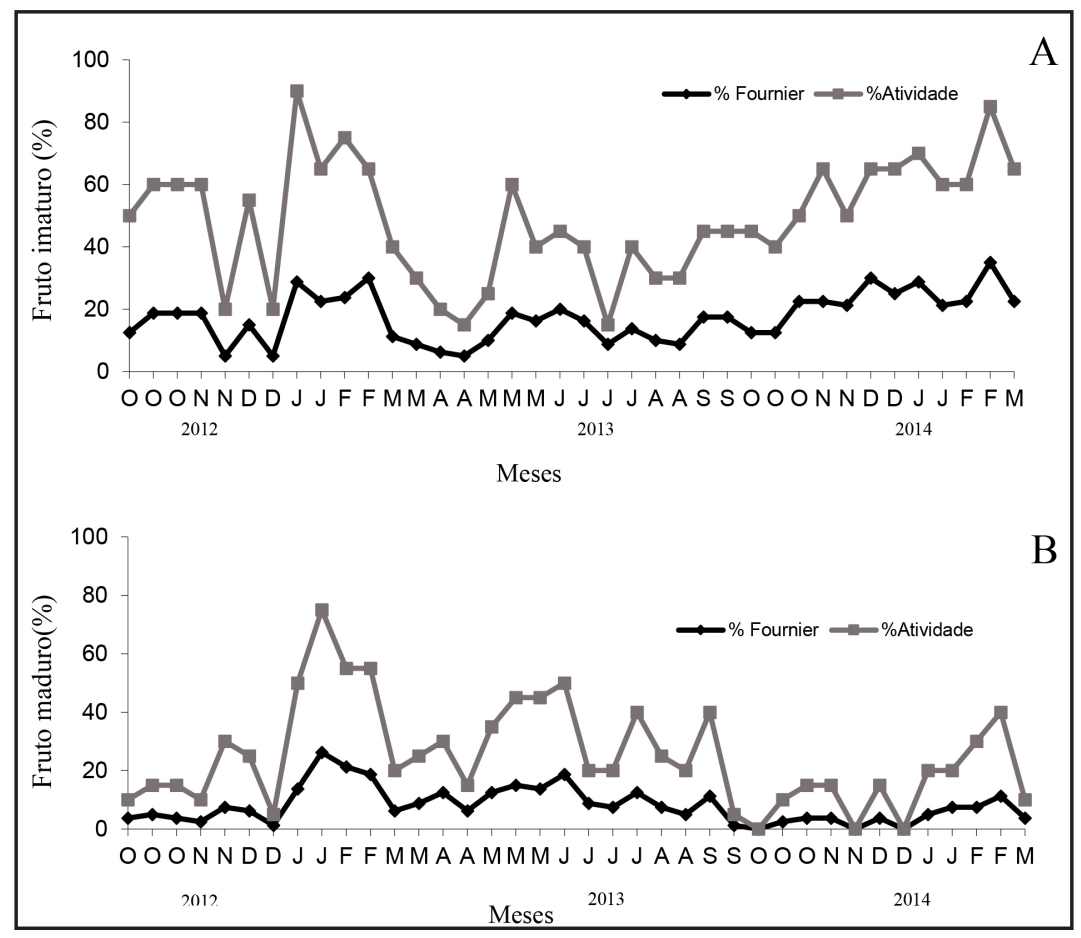

Fonte: Autores (2019) 


\section{Correlação entre os dados fenológicos e as variáveis climáticas}

Há uma frequente relação entre a fenologia de plantas de regiões tropicais e o clima (WRIGHT; VAN SCHAIK, 1994). A correlação entre as variáveis climáticas e a intensidade de desfolhamento da Elaeis guineensis foi significativa no que tange à umidade relativa do ar, visto que em uma quinzena houve significância positiva entre a umidade e a senescência de folhas, ou seja, no período de 15 dias anteriores à observação dos indivíduos, quanto maior a umidade, maior foi a intensidade da queda de folhas (Tabela 1). No entanto, mesmo não havendo significância estatística entre os eventos de precipitação e temperatura, é necessário frisar que as plantas possuem uma resposta lenta a estes estímulos ambientais (MARQUES et al., 2004) e que, portanto, fatores como o aumento da temperatura e o baixo índice pluviométrico podem ter influenciado, a longo prazo, a queda das folhas.

Essa resposta das plantas ao ambiente ocorre devido aos vários mecanismos de sobrevivência que concernem aos vegetais. Além do fechamento dos estômatos, as plantas perdem suas folhas para diminuir a quantidade de energia utilizada na fotossíntese, garantindo um mínimo existencial para superar a baixa quantidade de água (TAIZ; ZEIGER, 2006).

\section{Tabela 1 - Correlações de Spearman $\left(\mathbf{r}_{s}\right)$ entre a média quinzenal das variáveis climáticas e os eventos fenológicos vegetativos de Elaeis guineensis observados em Macaíba - RN.}

Table 1 - Spearman correlations $\left(r_{s}\right)$ between the average fortnightly climate variables and vegetation phenology of Elaeis guineensis observed in Macaíba, RN state.

\begin{tabular}{lcccc}
\hline & \multicolumn{2}{c}{ Desfolhamento } & \multicolumn{2}{c}{ Enfolhamento } \\
\hline Tme & Atividade & Intensidade & Atividade & Intensidade \\
Ur & $n s$ & $n s$ & 0,417 & 0,540 \\
Pre & $n s$ & 0,401 & $-0,611$ & $-0,433$ \\
\hline
\end{tabular}

Em que: $n s=$ correlação não significativa $(\alpha=0,05)$; Tme = temperatura; Ur = umidade relativa; Pre = precipitação.

De acordo com os dados, verifica-se que quanto maior for a temperatura, menor for a umidade e menor a quantidade de chuvas, maior é a intensidade de enfolhamento da palmeira Elaeis guineensis (Tabela 1). Coincidentemente, quando o índice pluviométrico é baixo, há maior perda de folhas. Portanto, para sobreviver, Elaeis guineensis precisa produzir novas folhas, ou seja, a senescência destas no período seco diminuiria a perda de água pelo vegetal, contribuindo para o brotamento; evento repetidamente encontrado em espécies tropicais (BARBOSA et al., 1989; REICH; BORCHERT, 1984).

A causa para o não surgimento de botões florais e a abertura de flores está diretamente relacionada com o ambiente, uma vez que o clima ideal para o surgimento de inflorescências compreende chuvas uniformemente distribuídas ao longo do ano, cerca de 2.000 milímetros, e sem estações secas marcantes (BERGERT, 2000), o que se contrapõe à situação ambiental em análise, em que a precipitação chega à $1.220 \mathrm{~mm}$ por ano, prejudicando o desenvolvimento sadio da inflorescência do dendezeiro, influenciando na redução de cachos e na maior proporção de inflorescência masculina, tornando difícil a visualização das flores. Ainda, é necessário frisar que características próprias da espécie vislumbram a sua reprodução, a qual se caracteriza por períodos produtivos intercalados de dois anos (ADAM et al., 2005).

A relação entre a atividade de frutos imaturos e a temperatura foi significativa e positiva, sendo então produzida maior quantidade de frutos imaturos quanto maior a temperatura do ambiente (Tabela 2). Já quanto aos frutos maduros, a relação entre a intensidade destes e a 
umidade foi significativa e positiva, assim como a relação entre a intensidade e a precipitação. A atividade dos frutos maduros teve correlação significativa e positiva também com a umidade e a precipitação. Portanto, quanto maior a umidade e quanto maior o volume pluviométrico, maior é a produção de frutos maduros, comprovando a máxima de que quanto mais água, melhor é a produção de frutos carnosos (VIEIRA; CARVALHO, 2009). Isso explica a baixa produção de frutos maduros na população de Elaeis guineensis em Macaíba - RN, visto que há um baixo volume pluviométrico na região.

\section{Tabela 2 - Correlações de Spearman $\left(r_{s}\right)$ entre variáveis climáticas e os eventos fenológicos} reprodutivos de Elaeis guineensis em Macaíba - RN.

Table 2 - Spearman correlations $\left(\mathrm{r}_{\mathrm{s}}\right)$ between the average fortnightly climate variables and reproductive phenology of Elaeis guineensis in Macaíba, RN state.

\begin{tabular}{lcccc}
\hline & \multicolumn{2}{c}{ Fruto imaturo } & \multicolumn{2}{c}{ Fruto maduro } \\
\hline & Atividade & Intensidade & Atividade & Intensidade \\
\hline Tme & 0,336 & $n s$ & $n s$ & $n s$ \\
Ur & $n s$ & $n s$ & 0,416 & 0,455 \\
Pre & $n s$ & $n s$ & 0,578 & 0,614 \\
\hline
\end{tabular}

Em que: $n s=$ correlação não significativa $(\alpha=0,05)$; Tme = temperatura; $\mathrm{Ur}=$ umidade relativa; Pre = precipitação.

Conforme Miller (2002), a baixa produção de frutos pode ser em decorrência de diversos fatores, como reduzida taxa de polinização e aborto de frutos em estádios iniciais de maturação. A baixa frutificação, pode ainda estar relacionada às condições do local de estabelecimento dos indivíduos, visto que além das características intrínsecas das espécies, as variações climáticas também influenciam a fenologia (FERRAZ et al., 1999). Segundo Adler et al. (1998), o número de flores produzidas por uma planta não representa necessariamente a quantidade de frutos imaturos que serão observados, da mesma maneira que a quantidade de frutos imaturos pode não resultar na mesma quantidade de frutos maduros. Dessa forma, estudos de biologia reprodutiva, de frequência e eficiência de polinizadores devem ser realizados para compreender melhor os mecanismos reprodutivos da espécie.

Logo, nota-se a influência das variáveis climáticas no desenvolvimento vegetativo da Elaeis guineensis, sendo um importante fator para determinar o estabelecimento da espécie no ambiente e as possíveis qualidades de seus frutos. Verifica-se então, que a temperatura, a umidade relativa do ar e a precipitação são determinantes na fenologia dos indivíduos da população, visto que as plantas utilizam vários mecanismos para se adaptar a esses eventos abióticos, os quais, junto a fatores bióticos, como a ação de patógenos ou o benefício de polinizadores, são formas de seleção natural de espécies (CHAPMAN et al., 2005).

\section{Conclusões}

Os indivíduos de Elaeis guineensis possuem suas fenofases vegetativas em atividade ao longo de todo o ano, sendo influenciadas, principalmente, pela umidade, temperaturas e precipitação. Já os frutos imaturos são produzidos com maior intensidade em altas temperaturas, e frutos maduros em elevada umidade e precipitação.

Dessa forma, as correlações entre dados climáticos e a fenologia das plantas é de suma importância para o entendimento dos fatores que influenciam mecanismos de desenvolvimentos do vegetal. O dendezeiro tem um ótimo desenvolvimento em ambientes de altas taxas pluviométricas e, quando em lugar seco, pode manifestar comportamentos diferentes, como a 
baixa intensidade de produção de frutos e de inflorescências.

\section{Referências}

ADAM, H. et al. Reproductive developmental complexity in the african oil palm (Elaeis guineensis, Arecaceae). American Journal of Botany, Montpellier, v. 92, n. 11, p. 1836-1852, 2005.

ADLER, G. H.; LAMBERT, T.D. Spatial and temporal variation in the fruiting phenology of palms in isolated atands. Plant Species Biology, Malden, v. 23, n. 1, p. 9-17. 2008.

ALENCAR, J. C. Fenologia de cinco espécies arbóreas tropicais de Sapotaceae correlacionada a variáveis climáticas na Reserva Ducke, Manaus - AM. Acta Amazônica, Manaus, v.24, n. 3/4, p. 161-182, 1994.

ANDERSON, A. B.; OVERAL, W. L.; HENDERSON, A. Pollination ecology of a forest-dominant palm (Orbignya phalerata Mart.) in Northern Brazil. Biotropica, Washington, v. 20, n. 3, p. 192205, 1988.

BARBOSA, D. C. et al. Dados fenológicos de 10 espécies arbóreas de uma área de caatinga (Alagoinha-PE) Acta Botânica Brasílica, Porto Alegre, v. 3, n. 2, p.109-117, 1989.

BERGERT, D. L. Management strategies of Elaeis guineensis (oil palm) in response to localized markets in south eastern Ghana, West Africa. 2010. 120 f. Dissertação (Mestrado) - Master of science in forestry Michigan Technological University, Michigan. 2000.

CHAPMAN C. A. et al. A long-term evaluation of fruiting phenology: importance of climate change. Journal of Tropical Ecology, Cambridge, v. 21, n. 1, p. 1-14, 2005.

CORLETT, R. T. Reproductive phenology of Hong Kong shrubland. Journal of Tropical Ecology, Cambridge, v. 9, n. 4, p. 501-510, 1993.

CORLEY R. H. V.; HARDON J. J.; WOOD B. J. Germination and seedling growth. Developments in crop science oil palm research, Amsterdam, v. 2, n. 1, p. 23-36, 1976.

FEDERACIÓN NACIONAL DE CULTIVADORES DE PALMA DE ACEITE. Statistical Yearbook 2010. Fedepalma, Bogotá, Colombia. 2010.

FERRAZ, D. K.; ARTES, R.; MANTOVANI, W.; MAGALHÃES, L. M. Fenologia de árvores em fragmento de mata em São Paulo, SP. Brazilian Journal of Biology, São Carlos, v. 59, n. 2, p. 305$317,1999$.

FISCH, S. T. V.; NOGUEIRA JÚNIOR., L. R.; MANTOVANI. W. Fenologia reprodutiva de Euterpe edulis Mart. na Mata Atlântica (Reserva Ecológica do Trabiju, Pindamonhangaba - SP). Revista Biociências, Taubaté, v. 6, n. 2, p. 3137, 2000.

FOURNIER, L. A. Um método cuantitativo para la medición de características fenológicas em árboles. Turrialba, San Jose, v.24, n.4, p. 422-423, 1974.

GENTY, P. et al. Polinización entomófila de la palma africana en América tropical. Oléagineux, Montrouge, v. 6, n. 3, p. 99-112, 1986.

HAYATI, A. et al. Genetic diversity of oil palm (Elaeis guineensis Jacq.) germplasm collections from Africa: implications for improvement and conservation of genetic resources. Theoretical and Applied Genetics, Berlin, v. 108, n. 7, p. 1274-1284, 2004.

HUETE, A. R. et al. Amazon rainforests green-up with sunlight in dry season. Geophysical Research Letters, Washington, v. 33, n. 6, p. 1-4, 2006.

IBGE - FUNDAÇÃO INSTITUTO BRASILEIRO DE GEOGRAFIA E ESTATÍSTICA. Classificação da vegetação brasileira, adaptada a um sistema universal. BRASIL, IBGE, Rio de 
Janeiro, 1992. 124 p.

LIN, H. C. et al. Transcriptome analysis during somatic embryogenesis of the tropical monocot Elaeis guineensis: evidence for conserved gene functions in early development. Plant Molecular Biology, Dordrecht, v. 70, n. 1-2, p. 173-192, 2009.

LORENZI, H. et al. Palmeiras brasileiras exóticas e cultivadas. Nova Odessa, SP: Instituto Plantarum. 2004. p. 416.

MARQUES, M. C. M.; ROPER, J. J.; SALVALAGGIO, A. P. B. Phenological patterns among plant life forms in a subtropical forest in Southern Brazil. Plant Ecology, Dordrecht, v. 173, n. 2, p. 203-213, 2004.

MILLER, C. Fruit production of the ungurahua palm (Oenocarpus bataua subsp. Bataua, Arecaceae) in an indigenous managed reserve. Economic Botany, Bronx, v. 56, n. 2, 165-176, 2002.

REBELATTO, D.; LEAL, T. S.; MORAES, C. P. Fenologia de duas espécies de ipê em área urbana do município de Araras, São Paulo, Brasil. Revista da Sociedade Brasileira de Arborização Urbana, Piracicaba, v. 1, n. 8, p.1-16, 2013.

REICH, P. B.; R. BORCHERT. Changes with leaf age in stomatal function and water status of several tropical tree species. Biotropica, Washington, v. 20, n.1, p. 60-69, 1988.

SCARIOT, A. O.; LLERAS, E.; HAY, J. D. Reproductive biology of the palm Acrocomia aculeata in Central Brazil. Biotropica, Washington, v. 23, n. 1, p. 12-22, 1991.

SILVA, C. F.; CAVALCANTI L. H. Myxobiota of the Brazilian Atlantic Forest: species on oil palm tree (Elaeis guineensis, Arecaceae). Rodriguésia, Rio de Janeiro, v. 61, n. 4, p. 575-583, 2010.

STATSOFT, INC. STATISTICA (data analysis software system), version 10, 2011. www.statsoft. com.

TABARELLI, M.; VICENTE, A.; BARBOSA, D. C. A. Variation of seed dispersal spectrum of woody plants across a rainfall gradient in northeastern Brazil. Journal of Arid Environmental, [S.I], v. 53, p. 197-210, 2003.

TAIZ, L.; ZEIGER, E. Fisiologia vegetal. 3.ed. Porto Alegre: Artmed, 2006. 719 p.

VIEIRA, F. A.; CARVALHO, D. Maturação e morfometria dos frutos de Miconia albicans (Swartz) Triana (Melastomataceae) em um remanescente de floresta estacional semidecídua montana em Lavras, MG. Revista Árvore, Viçosa, v. 33, n. 6, p. 1015-1023, 2009.

VIlelA, G. F.; CARVAlHo, D.; VIEIRA, F. A. Fenologia de Caryocar brasiliense Camb. (Caryocaraceae) no Alto Rio Grande, Sul de Minas Gerais. Cerne, Lavras, v. 14, p. 317-329, 2008.

WRIGHT, S. J.; VAN SCHAIK, C. P. Light and the phenology of tropical trees. The American Naturalist, Chicago, v. 143, p. 193-199, 1994. 